\title{
APROXIMAÇÕES ENTRE A ETNOGRAFIA ARQUEOLÓGICA E OS MODOS DE FAZER NA COMUNIDADE QUILOMBOLA DE ITAMATATIUA, ALCÂNTARA - MARANHÃO
}

\section{RESUMO}

O ofício ceramista é uma das atividades mais complexas entre os povos do mundo. Dominar a manipulação da argila envolveu, durante milênios, elementos técnicos que estão presentes nas histórias e memórias das sociedades. Este artigo apresenta algumas reflexões sobre a pesquisa Um saber ancestral: documentação e extroversão da produção ceramista artesanal na comunidade quilombola de Itamatatiua, Alcântara - MA. Por meio de uma abordagem colaborativa com as ceramistas artesãs e sob o viés da etnografia arqueológica, enfocamos uma variedade de temas, como o modo de fazer cerâmica, a temporalidade do ofício, o domínio das técnicas, a cadeia operatória da produção artefatual, a territorialidade, a memória, as narrativas históricas e a identidade deste grupo quilombola. Neste artigo serão apresentados alguns resultados relacionados ao fazer cerâmico, que consideramos como um dos principais bens culturais do Maranhão que necessita ser conhecido, divulgado e salvaguardado.

PALAVRAS-CHAVE: etnografia arqueológica, modo de fazer, cerâmica, quilombo, Itamatatiua.

\section{ABSTRACT}

The ceramist trade is one of the most complex activities among the peoples of the world. Mastering the manipulation of clay has for millennia involved technical elements that are present in the stories and memories of societies. This article presents some reflections about the research An ancestral knowledge: documentation and extroversion of artisanal ceramist production in the quilombola community of Itamatatiua, Alcântara - MA. Through a collaborative approach with artisan ceramists and under the bias of archaeological ethnography, we focus on a variety of topics such as the way of making pottery, the temporality of the craft, the mastery of techniques, the operative chain of artefact production, territoriality, the memory, the historical narratives and the identity of this quilombola group. In this article we will present some results related to ceramic making, which we consider as one of the main cultural assets of Maranhão that needs to be known, divulged and safeguarded.

KEYWORDS: archaeological ethnography, way of making, ceramic, quilombo, Itamatatiua.

\section{RESUMEN}

El oficio ceramista es una de las actividades más complejas entre los pueblos del mundo. Dominar la manipulación de la arcilla involucró durante milenios elementos técnicos que están presentes en las historias y memorias de las sociedades. Este artículo presenta algunas reflexiones sobre la investigación Un saber ancestral: documentación y extroversión de la producción ceramista artesanal en la comunidad quilombola de Itamatatiua, Alcántara

\footnotetext{
${ }^{1}$ Doutor em Arqueologia. Docente da Universidade Federal do Maranhão - Campus de Pinheiro. Professor Permanente do Programa de Pós-graduação Interdisciplinar em Cultura e Sociedaldade. Coordenador do Observatório Cultural do Maranhão. E-mail: arkleymbandeira@gmail.com.
}

\begin{tabular}{|l|l|l|l|l|l|l|l}
\hline (C) Rev. Arqueologia Pública & Campinas, SP & v. & n. & p. & mês/ano & ISSN 2237-8294
\end{tabular}


- MA. Por medio de una aboardación colaborativa con las ceramistas artesanas y bajo el sesgo de la etnografía arqueológica, enfocamos una variedad de temas como el modo de hacer cerámica, la temporalidad del oficio, el dominio de las técnicas, la cadena operatoria de la producción artefatual, la territorialidad, la memoria, las narrativas históricas y la identidad de este grupo quilombola. En este artículo se presentarán algunos resultados relacionados con el hacer cerámico, que consideramos como uno de los principales bienes culturales de Maranhão que necesita ser conocido, divulgado y salvaguardado.

PALABRAS CLAVE: etnografía arqueológica, modo de hacer, cerámica, quilombo, Itamatatiua.

\section{INTRODUÇÃO}

A Comunidade Quilombola de Itamatatiua é um dos maiores povoados do município de Alcântara - Maranhão. Ela está situada entre as Reentrâncias Maranhenses e a Baixada Maranhense a cerca de $50 \mathrm{~km}$ da sede, sendo formada por pouco mais de 120 famílias, que correspondem a 450 habitantes. Itamatatiua tem 321 anos e, segundo Oosterbeek e Reis (2012), sua fundação ainda é muito discutida na comunidade. Contudo, a documentação informa que as origens do povoamento remetem à existência de uma fazenda da Ordem Carmelita na região, que após o declínio do período escravocrata foi extinta, e as terras remanescentes foram deixadas para a população afrodescendente, que iniciaram a ocupação da área. Para a região foram trazidos africanos das etnias Banto e Mina-Jeje.

A localização do município de Alcântara é ilustrada na Figura 1.

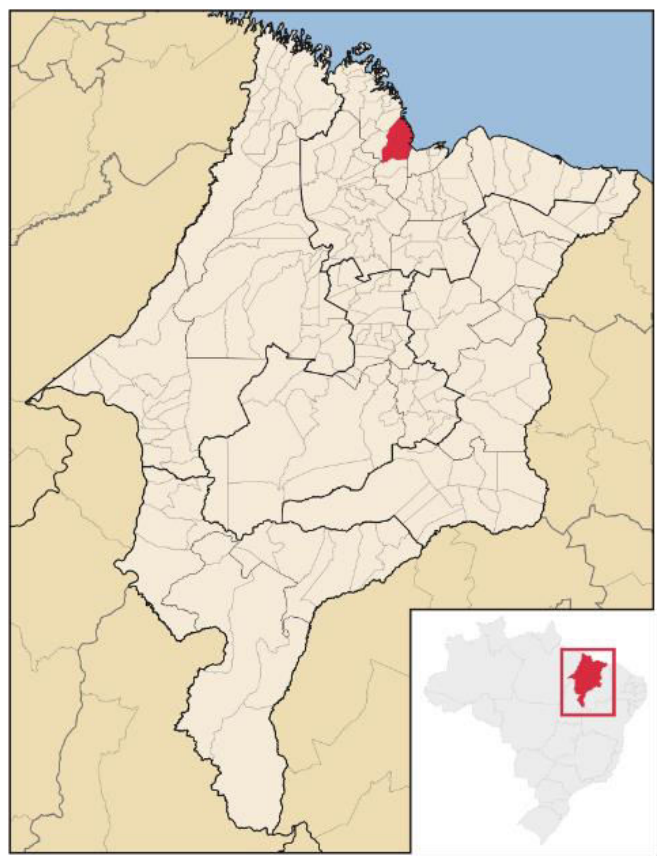

Figura 1. Município de Alcântara - MA, onde se localiza a Comunidade Quilombola de Itamatatiua.

Fonte: Google Maps.

A territorialidade e o modo de vida quilombolas são as características mais marcantes de Itamatatiua, com a existência de culto aos santos, rodas de tambor e outras celebrações. Há também a agricultura de subsistência, como a roça de coivara, coleta do babaçu, criação de pequenos animais para o consumo próprio e a organização espacial das casas em torno da igreja e do

\begin{tabular}{|l|l|l|l|l|l|l|} 
(C) Rev. Arqueologia Pública & Campinas, SP & v. & n. & p. & mês/ano & ISSN 2237-8294
\end{tabular}


cemitério, que ocupam a porção central e mais alta do sítio, com as casas dispostas em linha, ao longo de um caminho. Cabe destacar o festejo anual para a padroeira do povoado, Santa Tereza D'ávila ou Santa Tereza de Jesus, santa protetora da Ordem do Carmo, realizado no mês de outubro.

A imagem a seguir oferece um panorama aéreo do núcleo central e mais importante de Itamatatiua (Figura 2).

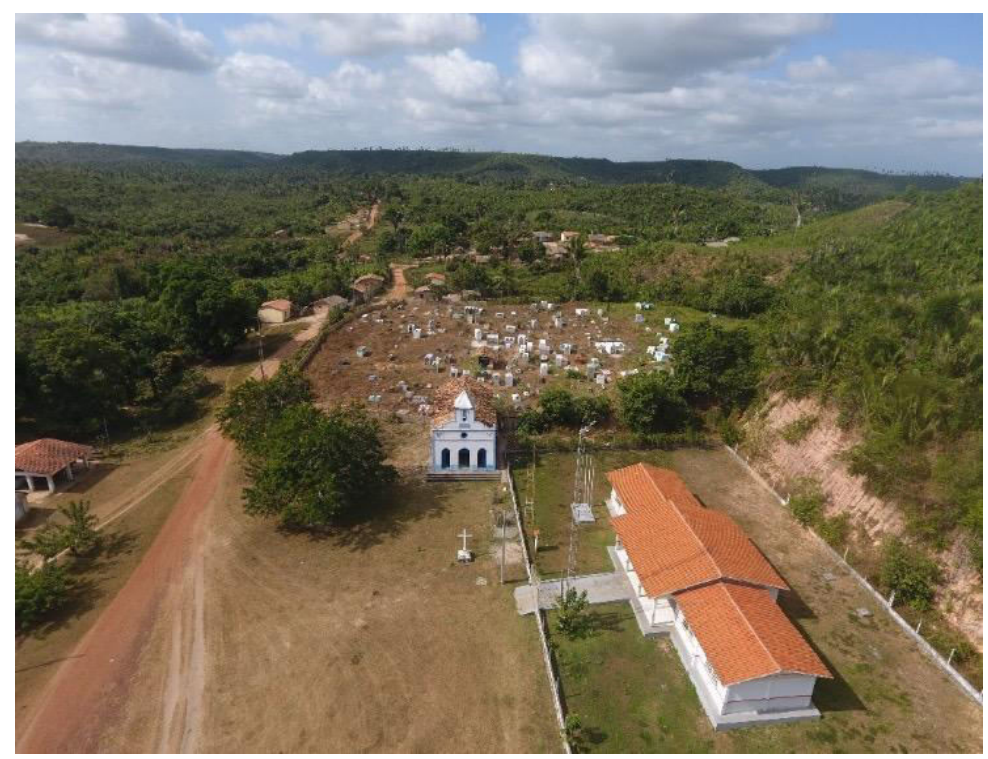

Figura 2. Vista aérea da Comunidade quilombola de Itamatatiua. Foto: Leonardo Soares (2017).

Os bens de interesse cultural da comunidade são formados por lugares e espaços sagrados (cemitério, igreja, casas de farinha, Fonte do Chora, Pedra de Encantaria e outros), marcos topofílicos, além do ofício artesanal da cerâmica, objeto de pesquisa da presente investigação. Destacam-se também as celebrações, rezas, crenças, festas de santo, tambores, dentre outros na esfera do intangível. Nas imagens a seguir, destacamos a fachada da Igreja de Santa Tereza D'ávila (Figura 3) e uma das pedras de fundação do povoado de Santa Thereza, protegida pelas ceramistas, cujas inscrições estão cunhadas em pedra de cantaria (Figura 4).
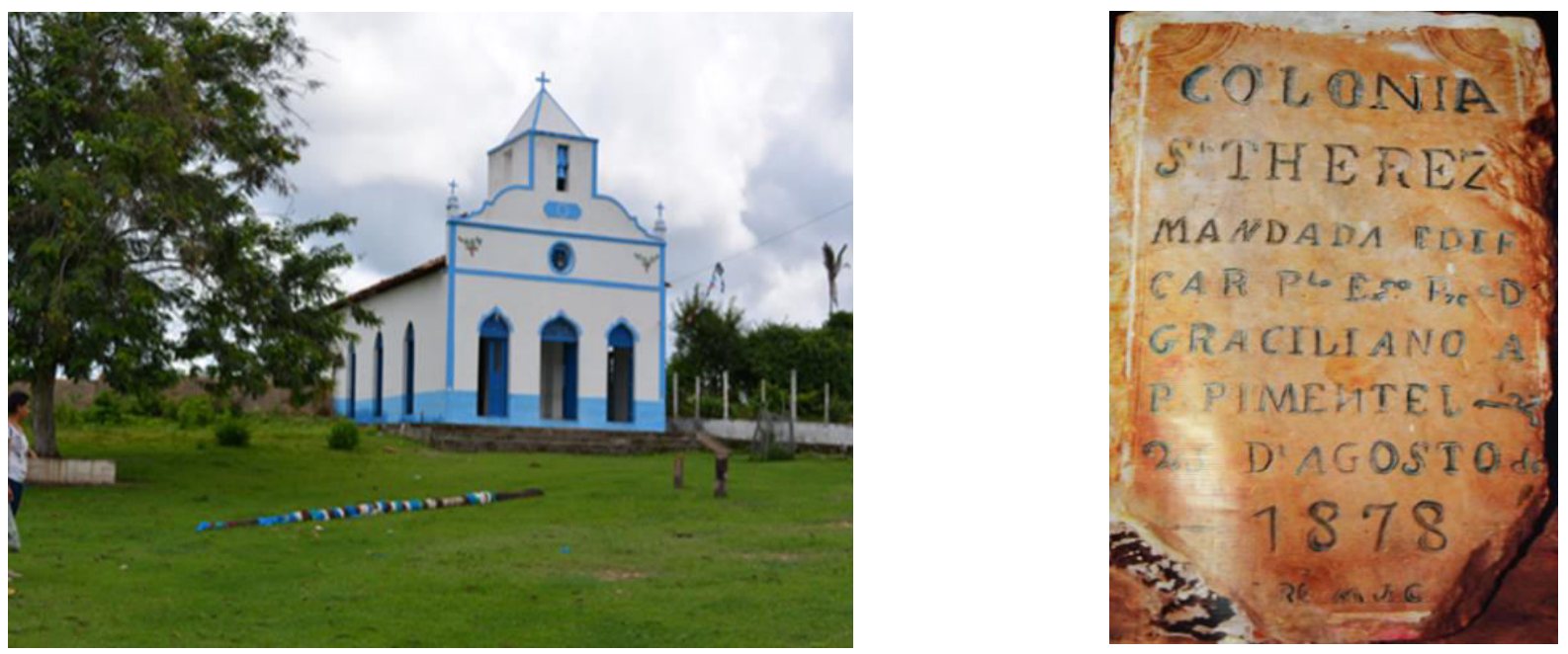
Figura 3. Igreja da padroeira da comunidade, Figura 4. Pedra de fundação da Colônia, marco Santa Tereza D'ávila. Foto: Arkley Bandeira histórico da comunidade. Foto: acervo dos (2016). moradores.

É nesse território que estamos desenvolvendo junto à comunidade um projeto de pesquisa com forte interface com a extensão universitária denominado Um saber ancestral: documentação e extroversão da produção ceramista artesanal na comunidade quilombola de Itamatatiua, Alcântara $M A^{2}$. Essa iniciativa vem construindo uma rede de relações colaborativas para compreender alguns dos principais suportes de memória e história ainda presentes na região, que são o ofício ceramista e a manutenção de uma tecnologia imemorial de manufatura. Estes se utilizam de matérias-primas locais coletadas em um amplo território, que aglutinam as fontes de argila, áreas para coleta do taquipé (itaquipé), locais para busca de lenha, caminhos de escoamento e vendas dos produtos, dentre outros.

Nas imagens a seguir, apresentamos a entrada de Itamatatiua, caracterizada por dois elementos que têm relação com a identidade dessa população: a imagem de Santa Tereza D'ávila e um pote cerâmico (Figura 5), ao passo que na Figura 6 observamos o galpão de produção.
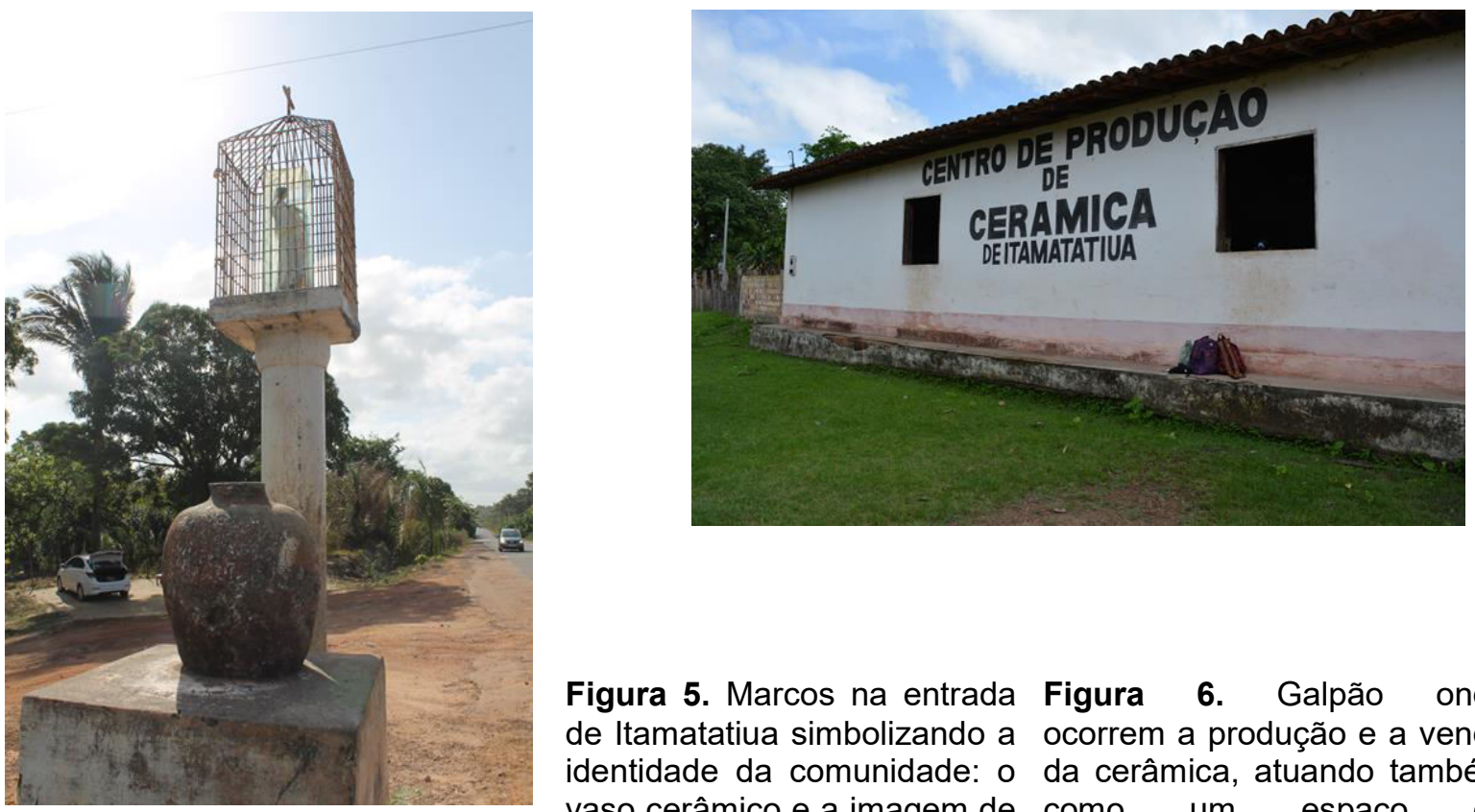

Figura 5. Marcos na entrada Figura 6. Galpão onde de Itamatatiua simbolizando a ocorrem a produção e a venda identidade da comunidade: o da cerâmica, atuando também vaso cerâmico e a imagem de como um espaço de Santa Tereza D'ávila. Foto: resistência e manutenção das Arkley Bandeira (2017). tradições ancestrais. Foto: Arkley Bandeira (2017).

Nesse sentido, os principais aspectos que vêm sendo abordados na pesquisa são a produção artesanal da cerâmica e a importância do seu papel nas relações sociais, culturais, econômicas, identitárias e de gênero; a temporalidade do modo de fazer, o domínio das técnicas e as expectativas das ceramistas de Itamatatiua acerca do alcance de seus produtos cerâmicos para o grande público. No âmbito da documentação, apesar da cerâmica ser a materialização de uma ação, os domínios que envolvem a sua produção artesanal se ancoram em experimentações, negociações, colaborações, transmissões, aperfeiçoamentos, adaptações, valorização, significação,

\footnotetext{
${ }^{2}$ Em junho de 2017, o Projeto foi contemplado pelo Edital Fapema 03/2017 - Programa de Apoio ao Patrimônio Imaterial do Maranhão - Processo 02016/17 - Termo: 015219/2017, favorecendo a construção de importantes ações para o ano de 2018
}

\begin{tabular}{|l|l|l|l|l|l|l|}
\hline (C) Rev. Arqueologia Pública & Campinas, SP & v. & n. & p. & mês/ano & ISSN 2237-8294
\end{tabular}


temporalidades, memórias, identidades e histórias, aspectos que se situam no universo do intangível e do imaterial.

A perspectiva adotada foca no ofício ceramista e nos produtos dele advindos como importantes referências sociais e culturais para a comunidade de Itamatatiua, investigando como ocorrem essas marcas distintivas entre os sujeitos envolvidos no processo produtivo ou os aspectos que os tangenciam. Logo, compreender o modo artesanal de fazer cerâmica como uma referência cultural significa dirigir o olhar para as representações que se materializam em uma "identidade ceramista" no território em foco, inclusive nas correlações com outros aspectos culturais relacionados à paisagem, edificações, "fazeres" e "saberes", crenças, celebrações, hábitos etc.

Para tanto, a pesquisa com o patrimônio imaterial não pode abrir mão da participação ativa e colaborativa da comunidade envolvida com as manifestações culturais. É ela que essencialmente deve ter voz na construção do conhecimento e nos apontamentos do que deve ser referenciado como relevante a ser salvaguardado. Logo, as ceramistas têm o papel não apenas de informantes, mas também são intérpretes de seu legado cultural.

Quando se trata de identificação, patrimonialização e proteção das referências culturais, a ação colaborativa é essencial para legitimar quais são as manifestações culturais mais significativas, sobretudo quando estão em jogo diferentes versões da identidade de um mesmo grupo (IPHAN, 2006). Nesse contexto, as ceramistas de Itamatatiua são partícipes ativas na construção da pesquisa, não somente como simples interlocutoras ou informantes, visto que o ato de identificar as referências culturais pressupõe não apenas a coleta de determinadas representações simbólicas, mas também a compreensão das relações entre elas e a construção de sistemas que "falem" daquele contexto cultural no sentido de representá-lo (IPHAN, 2000).

Nas palavras de Londres (2000, p. 20):

Identificar, na dinâmica social em que se inserem bens e práticas culturais, sentidos e valores vivos, marcos de vivências e experiências que conformam uma cultura para os sujeitos que com ela se identificam. Valores e sentidos esses que estão sendo constantemente produzidos e reelaborados, e que evidenciam a inserção da atividade de preservação de bens culturais no campo das práticas simbólicas.

Apesar de Itamatatiua ter sido objeto de estudo de muitos pesquisadores, que enfocaram distintas temáticas, a exemplo do modo de vida quilombola, territorialidade, celebrações, festas de santos, dentre muitas outras, a manufatura cerâmica só foi abordada parcialmente, especialmente pelo viés econômico, estético e funcional ou como um elemento a mais vinculado aos estudos naquela comunidade. Apesar disto, é ponto inconteste que um dos aspectos mais relevantes é o ofício tradicional da cerâmica e o seu papel identitário e mediador das relações sociais, culturais e econômicas entre os habitantes de Itamatatiua, especialmente entre as mulheres, conforme abordam diferentes autores (GRIJÓ, BERARDO, MENDONÇA, 2009; PEREIRA, 2011; JUNIOR, 2011, 2012; OOSTERBEEK, REIS, 2012; FERREIRA, 2012; CESTARIA, SANTOS, CARACAS, 2016).

\section{Aspectos teóricos e metodológicos: pressupostos sobre arqueologia colaborativa}

O estudo sobre os processos de manufatura da cerâmica feita por grupos tradicionais e a investigação das diferentes representações acerca da cerâmica enquanto mediadora das relações sociais, culturais e econômicas e como um importante suporte de histórias, memórias, identidades, materialidades e imaterialidades têm encontrado um terreno fértil nas regiões Nordeste e Norte do Brasil.

v. n.

n. $\quad$ p.

mês/ano


Convêm destacar alguns estudos colaborativos de cunho etnográfico, etnoarqueológico ou etnografia arqueológica, a exemplo dos trabalhos realizados por Fabíola Andrea entre os Asurini do Xingu, na T. I. Koatinemo ou Kuatinemu no Pará, que envolvem muitas temáticas de pesquisa, inclusive os estudos de objetos cerâmicos (SILVA, 2009; SILVA, GARCIA, 2015); os estudos de Raoni Valle e Claide de Paula Moraes, com os Zoé; os trabalhos de Márcia Bezerra entre os coletivos da vila de Joanes, na llha do Marajó, especialmente com a Associação Educativa Rural e Artesanal da Vila de Joanes - AERAJ (BEZERRA, 2014). No Nordeste brasileiro destacamos os trabalhos de Daniella Magri Amaral, com as "loiças" de barro em diferentes comunidades do Agreste de Pernambuco (AMARAL, 2012) e os de Herbert Moura Rego sobre a existência das panelas de barro, a partir de diferentes fontes de referência em Pernambuco (REGO, 2013), bem como as pesquisas de Luiz Antônio Pacheco de Queiroz acerca da cerâmica entre grupos tradicionais do Cariri Cearense (QUEIROZ, 2015).

A presente pesquisa insere-se no contexto anteriormente exposto e nasce de uma atividade de extensão denominada "Vivências Patrimoniais", idealizada pelo autor, que envolve o corpo discente do Curso de Licenciatura em Ciências Humanas, Campus Pinheiro da UFMA. As vivências patrimoniais são estratégias de ensino e pesquisa para envolver os discentes em torno de diferentes aspectos da região da Baixada Maranhense e Reentrâncias Maranhenses, que no caso do modo de fazer ceramista visa a irradiar as percepções para outros aspectos do universo de estudo, com temas geradores abertos que atuam como roteiros para construção de conhecimento junto às ceramistas.

Os temas foram divididos entre as equipes de pesquisa, que ficaram responsáveis pela elaboração e condução da coleta de dados. Os resultados foram tão exitosos que os discentes demandaram um maior aprofundamento da pesquisa, envolvendo outros aspectos do ofício ceramista e suas relações com a comunidade, justificando a construção de um objeto de investigação mais estruturado e global que pudesse se desdobrar em monografias e projetos de pósgraduação.

Diante disso, construímos um projeto de investigação com base na etnoarqueologia colaborativa que levasse em consideração as expectativas políticas das ceramistas e que possibilitasse construir uma agenda de trabalho conjunto que envolvesse as artesãs, o corpo discente e a produção do conhecimento sobre as práticas ancestrais ainda resilientes na região. Nesse contexto, optou-se por realizar uma etnografia arqueológica, a partir de uma miríade de problemas comuns, a exemplo da produção material, paisagem, territorialidade, agência, gênero, dentre outros.

A esse respeito, Fabíola Andrea Silva (2009) reconhece que a etnoarqueologia é uma especialidade da arqueologia que estuda as sociedades contemporâneas e a sua relação com o mundo material, constituindo um campo investigativo que visa a trazer referenciais etnográficos como subsídios às interpretações arqueológicas sobre o passado e, ao mesmo tempo, como uma possibilidade de "arqueologia do presente", conforme práxis cunhada por Alfredo González Ruibal (2009).

Na pesquisa em questão, não se busca uma etnoarqueologia de base processual que visa a construir analogias diretas, pelo contrário, intentamos desenvolver uma perspectiva muito mais alinhada ao que Gnécco (2012) denomina como "arqueologias alternativas", que se coloca em oposição à hegemonia da arqueologia positivista e cientificista.

Ressaltamos que a virada epistemológica para um fazer arqueológico colaborativo se deu pela abertura da disciplina para novas vozes e ampla aceitação de outras formas de construir

\begin{tabular}{|l|l|l|l|l|l|l|} 
(C) Rev. Arqueologia Pública & Campinas, SP & v. & n. & p. & mês/ano & ISSN 2237-8294
\end{tabular}


conhecimento, para além da colonialista ocidental, sobretudo com a aceitação de perspectivas pósprocessuais. Somam-se a isso as pesadas críticas ao modelo tradicional da etnoarqueologia, a exemplo de que a interpretação do registro arqueológico por analogia sempre seria subjetiva (ASCHER, 1961). Com isso, seria impossível construir estudos comparados concretos e diretos entre os povos atuais e a cultura material de grupos já extintos, pois nem sempre os dados etnográficos teriam correlatos arqueológicos (GOULD, 1978, 1980).

Para Silva (2009), a etnoarqueologia assentou-se em estratégias metodológicas diversificadas, mas que se complementam, a exemplo da pesquisa bibliográfica e museográfica, a pesquisa experimental e a pesquisa de campo etnográfica, com a total colaboração dos coletivos e povos. Nesse contexto, uma pesquisa etnoarqueológica feita no presente deve construir pontes com os coletivos sociais, visando a responder problemas arqueológicos.

Ao passo que arqueologia do presente, segundo Ruibal (2009), procura encontrar marcos de referências objetivos e contrastáveis que permitam compreender melhor o papel da ação humana, como os estudos de Deal (1998) sobre a produção cerâmica entre os Maias atuais. Logo, uma arqueologia do presente investiga as sociedades atuais por meio da etnografia, mas com as bases teóricas e metodológicas da arqueologia, e nisto ela é diferente à etnoarqueologia até então praticada (RUIBAL, 2006).

A arqueologia do presente é também uma etnografia no sentido que descreve sociedades vivas, buscando compreender suas relações com a materialidade e a imaterialidade. Portanto, ao trabalhar com os povos em situação de desestruturação social, violência política, programas de desenvolvimento, marginalidade e impotência frente aos embates com os Estados nacionais e à globalização, essa perspectiva se torna uma arqueologia política e crítica, que estuda potencialmente o mundo atual tanto em sociedades modernas quanto não capitalistas e, principalmente, não estabelecendo relações entre "nós" e os "outros" (RUIBAL, 2009).

Trata-se então de uma forma decolonial e comprometida em compreender as culturas locais e seus contextos históricos e políticos no presente por seus próprios termos, buscando engajamento social e colaboração, com ênfase em diversos temas, como contato cultural, hibridização, identidade étnica, tecnologia e sociedade e organização do espaço doméstico (RUIBAL, 2006, 2009).

Segundo Silva (2015), a "arqueologia colaborativa" pode ser concebida como uma investigação arqueológica/etnoarqueológica participativa que envolva a comunidade e os coletivos para além da mera consulta na condução da pesquisa ou fonte de informação para a busca de dados. Ela prima pelo engajamento crítico e interação dos grupos locais durante todo o processo de tomada de decisão e de construção do conhecimento. Essa perspectiva tende a superar posturas colonialistas tradicionais na prática da arqueologia, buscando evidenciar a pluralidade das vozes interpretativas do e sobre o passado (SILVA, 2012).

Nessa mesma linha, o que se intenta com a etnografia da produção ceramista no Quilombo de Itamatatiua, para além dos aspectos já descritos neste texto, é construir bases de referência para compreender a cadeia operatória da produção ceramista, primando por um viés colaborativo e participativo com as ceramistas por meio da observação participante dos modos de fazer e conceber o artefato cerâmico, ou seja, primando por uma "etnografia arqueológica".

Para Yannis Hamilakis (2011), a "etnografia arqueológica" pode ser concebida como um espaço transcultural para múltiplos encontros, conversas e intervenções, envolvendo pesquisadores de várias disciplinas e diversos públicos. Ela é centrada na materialidade e na multitemporalidade e

\begin{tabular}{|l|l|l|l|l|l|l|l}
\hline (C) Rev. Arqueologia Pública & Campinas, SP & v. & n. & p. & mês/ano & ISSN 2237-8294
\end{tabular}


tenta superar as incertezas da arqueologia convencional ao questionar princípios ontológicos, fundados na temporalidade modernista, linear e sucessiva. Essa perspectiva se ampara em premissas como as de Leach (1977), que enfatiza que a cultura material revelada pelas escavações não são "coisas em si" ou apenas artefatos feitos pelas pessoas, mas representam ideias.

A etnografia arqueológica deve ser multitemporal, sintonizada com as propriedades duracionais da matéria e preocupada com os vários modos sócio-vernaculares da percepção e historicização temporais. Nesse âmbito, Hamilakis (2011) argumenta que ela é muito mais que uma prática e um método, tratando-se de uma temática transdisciplinar e transcultural que permite múltiplos encontros, conversações e intervenções, além de potencializar percepções etnograficamente múltiplas e alternativas da materialidade e da temporalidade; propriedades e qualidades de objetos e coisas, taxonomias cronométricas, tipológicas, funcionais ou formais, dentre outros aspectos, permitindo que agências sejam encenadas por meio de performances contemporâneas, nas quais humanos, outros seres, objetos e coisas são protagonistas.

Alinhados com Hamilakis (2011), buscamos realizar na pesquisa uma etnografia total, mas não totalizante, enfatizando o contexto social e cultural do modo de fazer cerâmica, com ênfase na cadeia operatória deste ofício tradicional, compreendendo a produção ceramista com base na biografia do objeto (RUIBAL, 2009). A biografia do objeto refere-se à sua história de vida específica, que se estende desde a busca de matérias-primas até sua destinação final e descarte, porém, enfatizando as intrincadas relações históricas entre as pessoas e as coisas e as suas relações com o tempo presente.

A observação do modo de fazer cerâmica se inspirou nos pressupostos apresentados por Silva (2009, p. 132):

\begin{abstract}
Durante a pesquisa de campo, o etnoarqueólogo tem uma preocupação com o detalhamento das cadeias operatórias de produção dos itens materiais, descrevendo os processos tecnológicos desde a obtenção das matérias-primas até a confecção do produto final, seu uso, armazenagem e descarte, sempre atento aos vestígios materiais resultantes de todos esses processos. Paralelamente, se interessa em observar o modo como as pessoas usam o espaço, tanto para desenvolver essas atividades de produção quanto para realizar suas atividades cotidianas de subsistência, nesse caso, o universo de observação se estende para além dos assentamentos de moradia, a fim de se obter uma percepção do uso do território de ocupação dos grupos.
\end{abstract}

Pelo exposto, a metodologia empregada nesta pesquisa estruturou-se a partir dos pressupostos expostos anteriormente, utilizando-os como instrumento para coleta de dados o Inventário de Conhecimento ou Varredura desenvolvido pelo IPHAN, no âmbito da política nacional de patrimônio imaterial (IPHAN, 2000). Logo, a pesquisa etnográfica ${ }^{3}$ girou em torno do seguinte tema gerador: como o ofício da manufatura cerâmica tornou-se uma referência cultural para a comunidade de Itamatatiua?

Em relação ao inventário, Soares (2009, p. 286) conceitua-o:

O inventário é indicado nominalmente em dispositivo constitucional como um dos instrumentos para promoção e proteção do patrimônio cultural brasileiro. É um instrumento de proteção dos bens materiais e imateriais, móveis e imóveis, públicos ou privados, nacionais e estrangeiros. Além disso, pode ser feito por entes públicos e privados, com adoção de metodologia prédeterminada pelo órgão cultural ou com o uso de metodologia desenvolvida por outros experts ou profissionais que lidem com patrimônio cultural.

\footnotetext{
${ }^{3}$ A pesquisa etnográfica fundamenta-se na inserção do pesquisador em um campo diferente, do ponto de vista cultural, de seu próprio habitat durante um longo período. A prática etnográfica consiste basicamente em estabelecer relações, selecionar informantes e tentar salvar o dito em um discurso social em formas pesquisável (SOUSA; BARROSO, 2008). O pesquisador exercita a prática da observação, da descrição e da análise das dinâmicas interativas e comunicativas como uma das mais relevantes técnicas.
} 
O Inventário de Conhecimento ou Varredura é qualquer estudo que vise a conhecer o universo de um bem cultural de determinada região, podendo relacionar-se a um determinado tema, funcionando como um mapeamento abrangente, cujo objetivo final é o conhecimento, salvaguarda e proteção. "Inventariar" significa também encontrar, tornar conhecido, identificar; descrever de forma acurada cada bem considerado, de modo a permitir a sua adequada classificação. Ele exige uma rigorosa pesquisa, organização e sistematização das informações obtidas, que devem seguir as fases de desenvolvimento de uma pesquisa científica (IPHAN, 2006). A realização de um Inventário depende de que se definam e se tipifiquem de antemão as ocorrências concretas que serão consideradas pertinentes, que no caso em questão é o ofício da manufatura artesanal da cerâmica.

Nesta pesquisa, o inventário focaliza as dimensões apreensíveis sobre o ofício, a exemplo dos documentos escritos, audiovisuais, objetos, bem como os depoimentos e as narrativas orais que explicitem quais os aspectos mais relevantes para as ceramistas, quando se pensa as suas referências em relação à manufatura cerâmica. Esse é o primeiro nível da realidade a ser inventariada. Não obstante, a metodologia de pesquisa considera os objetos cerâmicos para além da sua materialidade, tentando evidenciar os valores e as significações enraizados nas práticas sociais, que ademais de intangíveis ou imateriais muitas vezes não chegam a ser explicitados ou nem mesmo afloram aos atores sociais de imediato (IPHAN, 2000).

\section{ALGUMAS CONSIDERAÇÕES...}

Conforme demonstrado ao longo do texto, o trabalho em questão está em pleno desenvolvimento tanto no aspecto do levantamento de informações, construção dos espaços colaborativos, percepção e mapeamentos de territórios quanto no que tange à construção do Inventário de Conhecimento e Varredura. Por se tratar de uma atividade colaborativa, a dinâmica da pesquisa respeita o planejamento e os direcionamentos das ceramistas, sobretudo quando a ação se relaciona com o deslocamento destas de sua área de residência ou do galpão de trabalho. Nesse sentido, as primeiras aproximações com a comunidade foram fundamentais para construir um diálogo em conjunto.

Um dos primeiros produtos gerados pelo viés colaborativo foi a construção dos mapas de percepção do território, envolvendo os locais de captação de argila, locais florestados para coleta da casca de árvore que serve como antiplástico, denominado taquipé (itaquipé), bem como áreas de roçados, marcos topofílicos, caminhos antigos e identificação de áreas com assentamentos antigos e sítios arqueológicos, além da coleta de informações individuais e coletivas sobre os eixos da pesquisa.

\begin{tabular}{l|l|l}
$\mathrm{v}$. & $\mathrm{n}$.
\end{tabular}

p. 


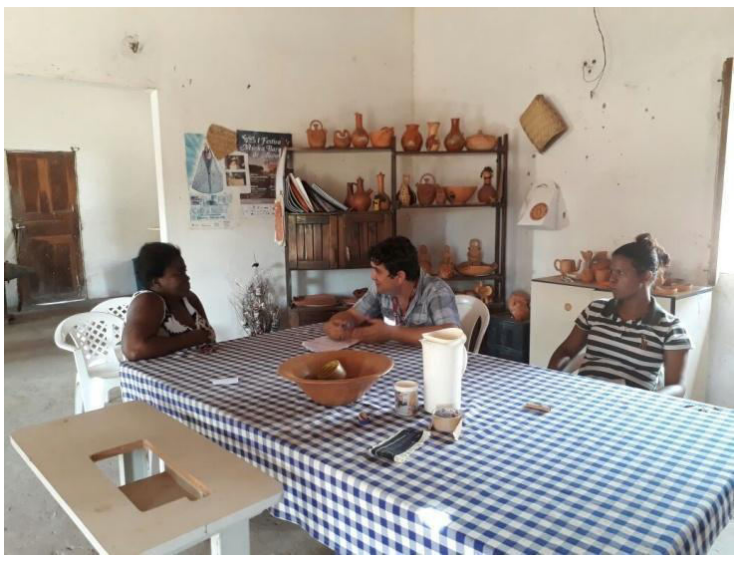

Figura 7- Dinâmicas coletivas e individuais para apresentação e definição dos eixos de trabalho de forma colaborativa. Foto: Chrystiane Campelo (2017).

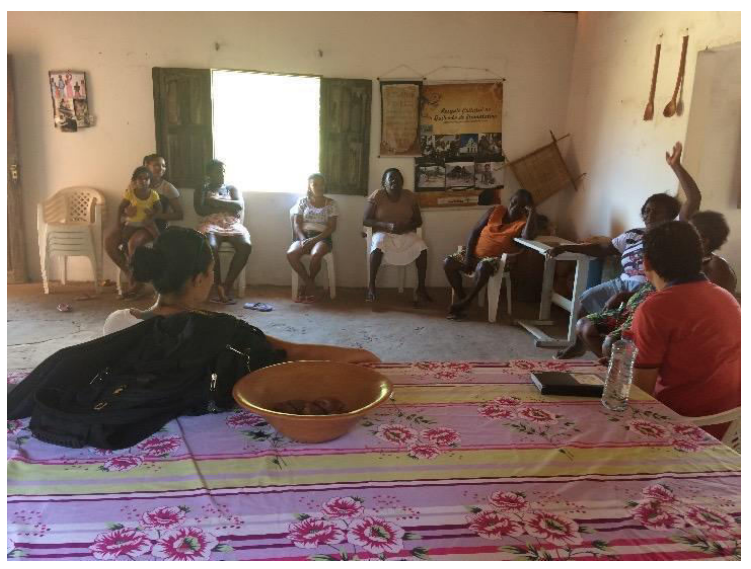

Figura 8 - Reunião para definição dos roteiros para reconhecimento do território nas áreas de coleta da argila e retirada do Taquipé. Foto: (2017). 


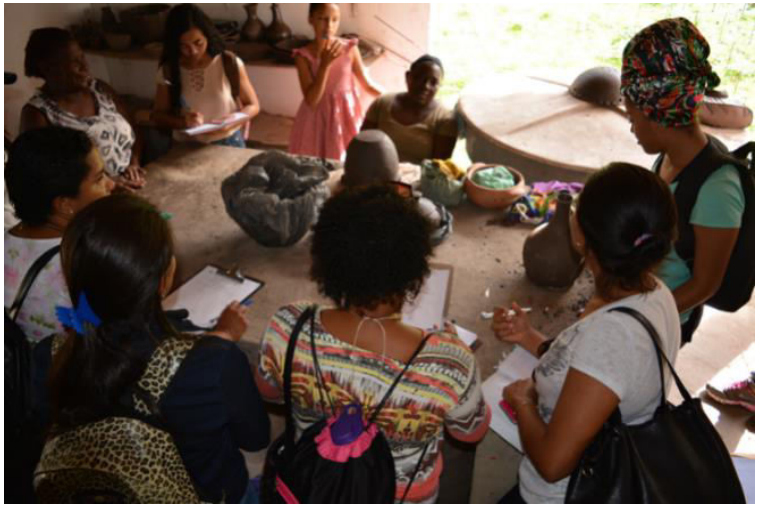

Figura 9. Roda de conversa para registro dos diálogos sobre a manufatura cerâmica. Foto: Arkley Bandeira (2016).

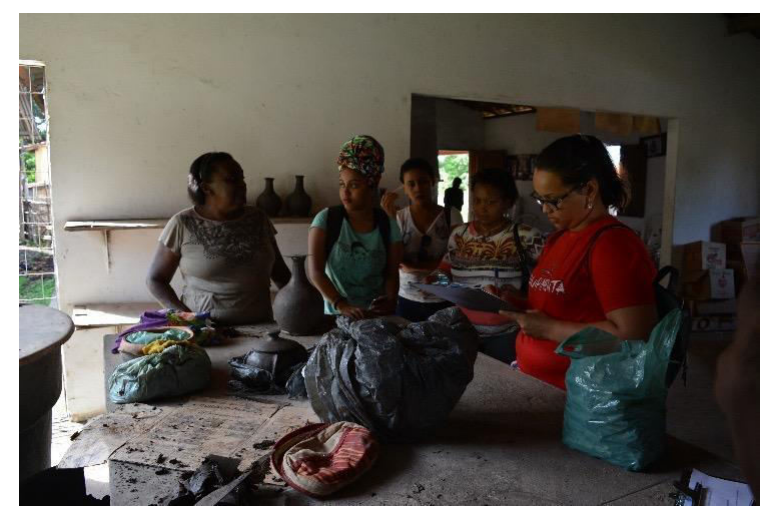

Figura 10. Conversas sobre os eixos da sustentabilidade e manufatura cerâmica. Foto: Arkley Bandeira (2016).

Contudo, enfatizaremos neste artigo a tecnologia de manufatura cerâmica abordando as observações empíricas construídas na documentação da cadeia operatória para elaboração dos artefatos em barro. Nesse contexto, cabe destacar que o modo de fazer cerâmica quilombola em Itamatatiua se assemelha bastante à tecnologia indígena brasileira, principalmente pelo uso dos roletes para construção e estruturação dos artefatos, técnica denominada de roletada ou acordelada.

Além disso, muitas denominações ainda utilizadas pelas ceramistas no processo produtivo remetem a corruptelas ou adaptações de línguas do Tronco Tupi. Tal situação é particularmente importante, visto que não existem populações indígenas autorreconhecidas ou oficiais na área da pesquisa. Logo, esses indícios vêm indicando fortes relações afro-indígenas, que estão perpetuadas nos fazeres, modos de ocupação do território, uso do espaço e tecnologias de cerâmica, cestaria, dentre outros, bem como no universo simbólico e nas religiosidades. A presença de material arqueológico pré-colonial, especialmente lâminas de machados em rocha polida e fragmentos cerâmicos pintados vêm confirmando a presença indígena na região em tempos imemoriais. Não obstante, a confirmação de possíveis contatos interétnicos entre os primeiros quilombolas de Itamatatiua com grupos indígenas na região em período Colonial é um viés ainda a aprofundar.

Especificamente sobre a tecnologia cerâmica, o processo de documentação registrou todo o processo produtivo, desde elaboração até a venda dos artefatos, conforme ilustrado a seguir.
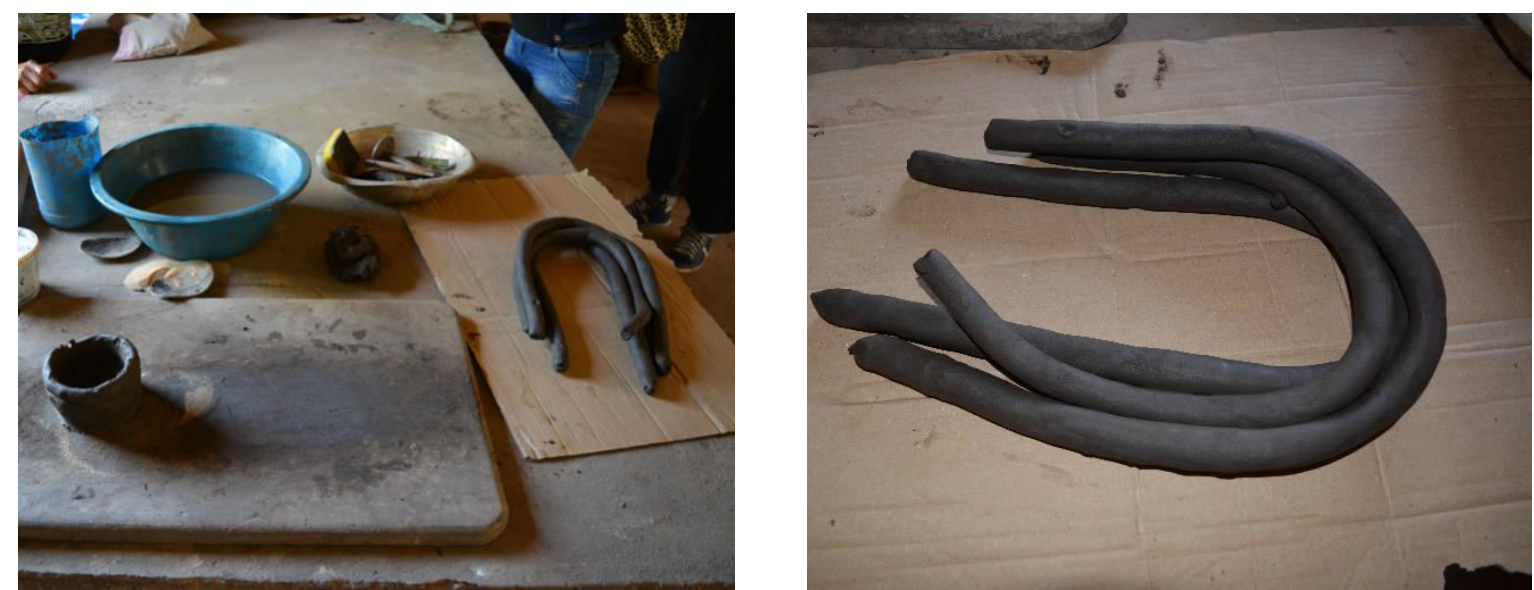
Figura 11. Equipamentos necessários à Figura 12. Roletes prontos para serem utilizados manufatura cerâmica sobre mesa de trabalho. na montagem dos vasos cerâmicos. Foto: Jane Foto: Arkley Bandeira (2016). (2017)

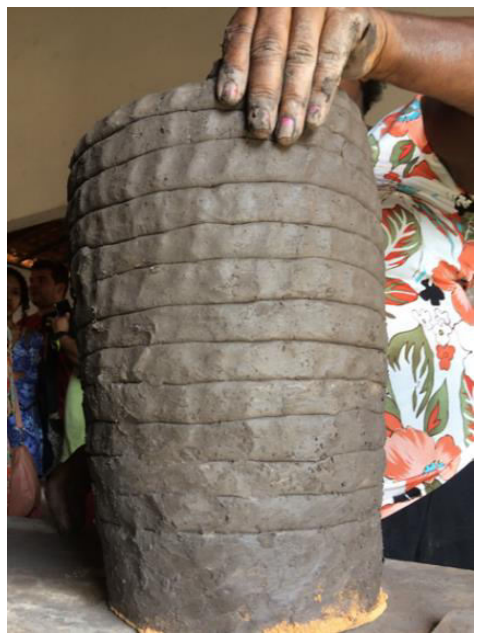

Figura 13. Vaso cerâmico estruturado com os roletes unidos. Foto: Arkley Bandeira (2016).

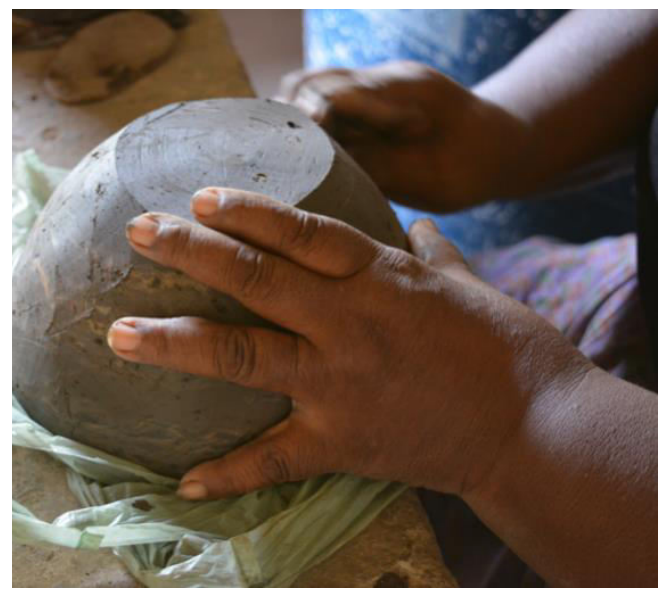

Figura 14. Processo de alisamento para junção dos roletes e retirada do excesso da argila. Foto: Arkley Bandeira (2017).

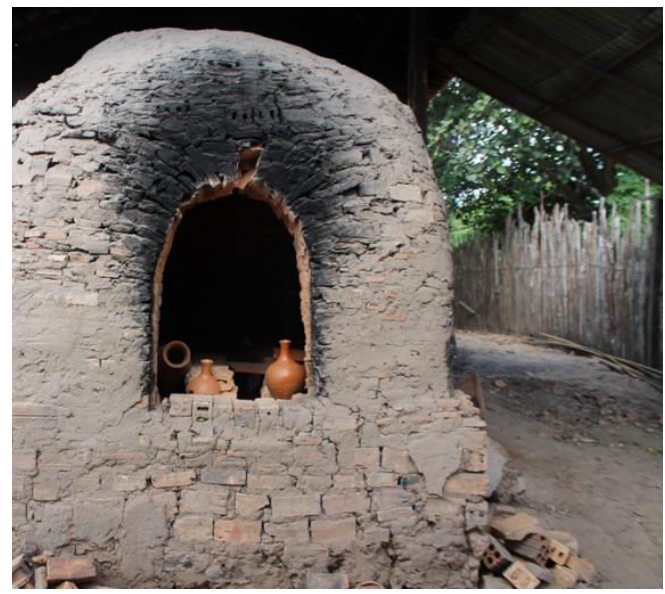

Figura 15. Vasos prontos para secagem pré- Figura 16. Forno de queima cerâmica, com queima. Foto: Arkley Bandeira (2016).

objetos já queimados em seu interior. Foto: Arkley Bandeira (2017).

Conforme apresentamos, o processo de manufatura cerâmica está inserido em códigos sociais e culturais transmitidos ancestralmente, que associam-se desde a busca das matériasprimas, a exemplo do taquipé, da argila, da areia e de outros elementos associados ao modo de fazer ceramista de Itamatatiua. Um aspecto que convém ser considerado é a montagem do artefato que se utiliza da técnica conhecida como acordelado, roletado ou sobreposição de roletes ou tiras, para posterior acabamento, secagem e queima da peça. Esse modo de fazer cerâmica, como já abordado ao longo do texto, remete a um saber ainda mais antigo relacionado aos grupos indígenas que ocuparam a região.

v.

n.

p.


Conforme também abordado, a pesquisa vem construindo fortes laços com a extensão universitária, ou seja, possibilitando o intercâmbio dos discentes, professores e a sociedade em geral com o universo cerâmico de Itamatatiua, por meio das vivências na comunidade e exposições itinerantes já realizadas, conforme demonstrado a seguir.

Ainda no âmbito da extensão, o cerne do conceito de referência cultural perpassa pela participação da comunidade de forma ativa e colaborativa na construção do conhecimento. Nesse contexto, já foram realizadas duas ações que envolveram a participação das ceramistas: a primeira foi uma oficina de manufatura cerâmica no âmbito da Semana de Consciência Negra da UFMA e na Escola Dom Ungarelli, em novembro de 2017, e a segunda ocorreu em dezembro de 2017 na I Jornada Internacional de Ciências Humanas da UFMA, onde foi realizada uma exposição das peças cerâmicas elaboradas especificamente para este fim, conforme ilustrado a seguir.

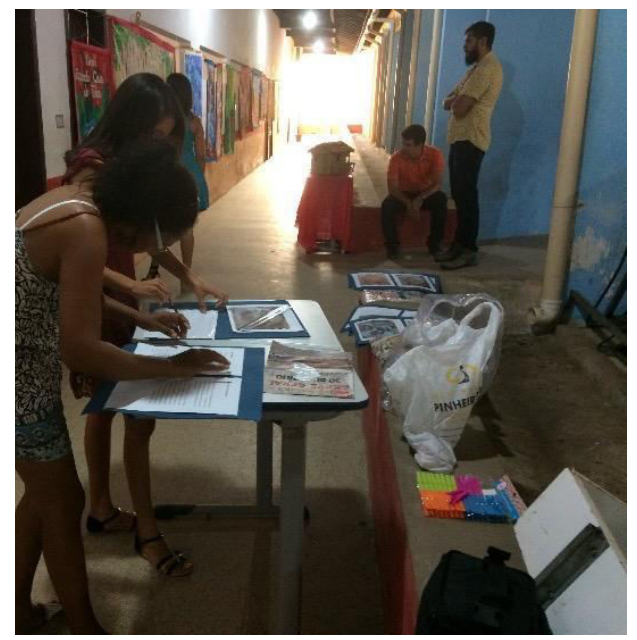

Figura 17. Montagem da exposição Um saber ancestral: documentação e extroversão da produção ceramista artesanal na comunidade quilombola de Itamatatiua, Alcântara - MA no II Encontro Floresta dos Guarás, em Cururupu MA. Foto: Arkley Bandeira (2017).

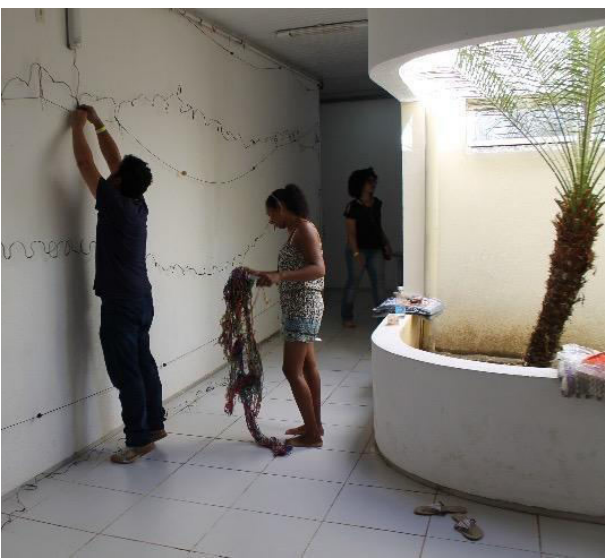

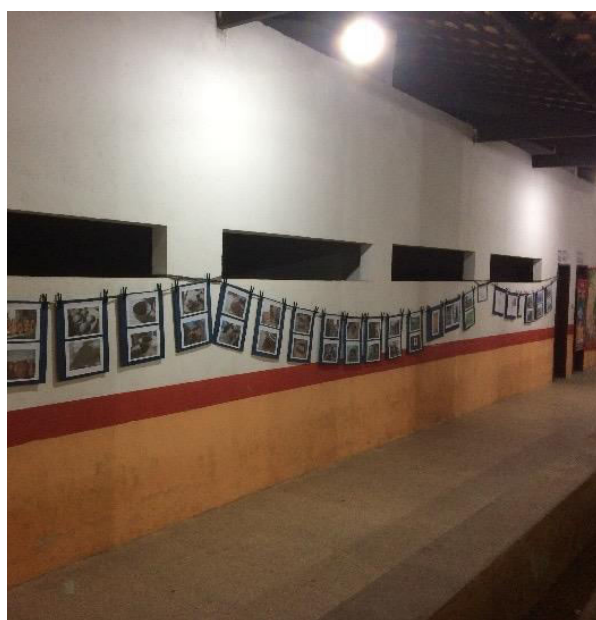

Figura 18. Exposição Um saber ancestral: documentação e extroversão da produção ceramista artesanal na comunidade quilombola de Itamatatiua, Alcântara - MA no II Encontro Floresta dos Guarás, em Cururupu - MA. Foto: Arkley Bandeira (2017).

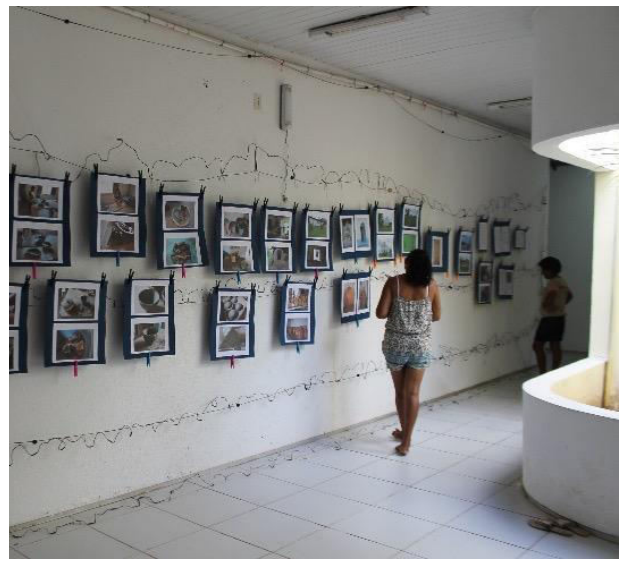


Figura 19. Montagem da exposição Um saber ancestral: documentação e extroversão da produção ceramista artesanal na comunidade quilombola de Itamatatiua, Alcântara - MA no VII Seminário de Pisicicultiura da Baixada Maranhense, em Pinheiro - MA. Foto: Arkley Bandeira (2017).
Figura 20. Vista da Exposição Um saber ancestral: documentação e extroversão da produção ceramista artesanal. Foto: Arkley Bandeira (2017).

\section{CONSIDERAÇÕES FINAIS}

Diante do exposto, seria redundante falarmos da relevância da temática abordada, principalmente pela participação ativa e colaborativa das ceramistas em todo o processo da etnografia arqueológica realizada, fato que vem fortalecendo as percepções sobre a cerâmica enquanto uma referência cultural, étnica e identitária da comunidade de Itamatatiua. A esse respeito, a construção de mecanismos de negociação e colaboração na construção de um conhecimento comum, distante do academicismo tão presente nas instituições de ensino superior, tem se mostrado uma ferramenta bastante eficaz para o empoderamento das ceramistas e para o reconhecimento de práticas ancestrais ainda resilientes no presente.

Apesar de considerarmos tratar-se de uma pesquisa etnográfica que começa a se estruturar e se consolidar em Itamatatiua, muitos avanços e conquistas já foram alcançados, conforme relatados ao longo do texto. Dentre eles, podemos destacar a importância do reconhecimento e valorização do ofício ceramista enquanto uma referência cultural dessa comunidade quilombola e sua relevância como suporte de memórias, histórias e identidades que vem agregando novas gerações em torno do fazer cerâmica.

O segundo aspecto recaiu sobre a região a ser estudada. A esse respeito, Anjos (2009) registrou a existência de 181 comunidades quilombolas apenas em Alcântara, das cerca de 899 já conhecidas no Maranhão, sendo uma das regiões do Estado com o maior número de territórios afrorremanescentes. Nesse contexto, o fato de Itamatatiua ser a única comunidade quilombola que ainda mantém o ofício ceramista é uma questão a ser mais bem trabalhada, documentada e promovida. Outro aspecto envolve a comunidade em uma perspectiva colaborativa e ativa, principalmente na construção das referências culturais sobre o ofício da cerâmica. Mapear conjuntamente as percepções sobre a cerâmica como artesanato ou objeto com valor social agregado, como mercadoria e/ou como suporte de histórias e memórias é um caminho ainda a ser percorrido pelas pesquisas na região.

Em relação à formação acadêmica dos discentes envolvidos na pesquisa, o contato com um universo até então desconhecido vem contribuindo para a formação profissional crítica, plural e multiétnica, sobretudo por cumprir o recomendado pelas Leis $n^{\circ}$ 10.639/03 e 11.645/08 (Art. 26-A da LDB) e a Resolução $n^{\circ} 1$, de 17 de junho de 2004, que instituem nas Diretrizes Curriculares Nacionais para a Educação o ensino de Relações Étnico-Raciais e o ensino de História e Cultura Afro-Brasileira, Africana e Indígena.

Por fim, convém frisar que ao longo dos próximos anos a pesquisa permanecerá construindo novas pontes e buscando desenvolver novas abordagens colaborativas, que serão divulgadas oportunamente.

\begin{tabular}{l|l|l}
$\mathrm{v}$. & $\mathrm{n}$.
\end{tabular}

p. 


\section{REFERÊNCIAS BIBLIOGRÁFICAS}

AMARAL, Daniella Magri. Loiça de Barro do Agreste: um estudo etnoarqueológico de cerâmica histórica pernambucana. São Paulo: Universidade de São Paulo, 2012.

(Dissertação de Mestrado em Arqueologia) - Universidade de São Paulo, São Paulo, 2012.

ANJOS, Rafael Sanzio Araújo dos. Quilombos: Geografia Africana - Cartografia Étnica Territórios Tradicionais. Brasília: Mapas Editora \& Consultoria, 2009.

ASCHER, Robert. Analogy in archaeological interpretation. Southwestern Journal of Anthropology, v. 17, p. 317-325, 1961.

BEZERRA, Márcia. As Cores do Passado na Amazônia: o patrimônio arqueológico no artesanato da Vila de Joanes, Ilha do Marajó, Brasil. Amazônica: Revista de Antropologia, v. 6, p. 418-441, 2014.

CESTARI, Glauba Alves do Vale, SANTOS, Denilson Moreira, CARACAS, Luciana Bugarin. A produção cerâmica no quilombo de Itamatatiua: interações entre artesanato tradicional e design com vistas à sustentabilidade. In: SANTOS, Denilsom Moreira et al. (Orgs.).

Artesanato no Maranhão: práticas e sentidos. São Luís: Edufma, 2016.

DEAL, M. Pottery ethnoarchaeology in the Central MaTa Highlands. The Universiry of Utah Press, Salt Lake Ciry, 1988.

FERREIRA, Rosinete de Jesus Silva. Nas tramas de Itamatatiua: as representações sociais da saúde e as trocas comunicativas dos filhos de Santa Teresa. Rio de Janeiro: UFRJ, 2012. (Tese de Doutorado) - UERJ, Rio de Janeiro, 2012.

GNECCO, Cristóbal. Escavando arqueologias alternativas. Revista de Arqueologia. São Paulo: Sociedade de Arqueologia Brasileira, v. 25, n. 1, p. 8-23, 2012.

GOULD, Richard. A. Beyond analogy in ethnoarchaeology. In: GOULD, Richard A. (Ed.). Explorations in ethnoarchaeology. Albuquerque: University of New Mexico Press, p. 239243, 1978.

. Living archaeology. Cambridge. Cambridge University Press, 1980. GRIJÓ, Wesley Pereira; BERARDO, Rosa Maria; MENDONÇA, Maria Luisa. A identidade na comunidade negra de Itamatatiua sob a perspectiva dos estudos pós-coloniais. Anais do V ENECULT - Encontro de Estudos Multidisciplinares em Cultura. Salvador: Faculdade de Comunicação/UFBA, 2009.

HAMILAKIS, Yannis. Archaeological Ethnography: A Multitemporal Meeting Ground for Archaeology and Anthropology. Annual Review of Anthropology, n. 40, p. 399-414, 2011.

JUNIOR, David Pereira. Tradição e identidade: a feitura de louça no processo de construção de identidade da Comunidade de Itamatatiua - e Alcântara Maranhão. In: MARTINS, Cynthia Carvalho et al. Insurreição de saberes: práticas de pesquisa em comunidades tradicionais. Manaus: Universidade do Estado do Amazonas - UEA, 2011.

\begin{tabular}{l|l|l} 
v. & n.
\end{tabular}

n.

p. 
Territorialidades e identidades coletivas: uma etnografia de Terra de Santa na Baixada Maranhense. Salvador: UFBA, 2012. (Dissertação de Mestrado. Programa de PósGraduação em Antropologia - PPGA) - UFBA, Salvador, 2012.

LEACH, Edmund. A view from the bridge. In: Archaeology and Anthropology: areas of Mutual Interest. Ed. M. Springs, p. 161-176, Oxford, 1977.

LONDRES, Cecilia. Referências culturais: base para novas políticas de patrimônio. Inventário Nacional de Referências Culturais: manual de aplicação. Brasília: Instituto do Patrimônio Histórico e Artístico Nacional, 2000.

IPHAN. Referências culturais: base para novas políticas de patrimônio. Inventário Nacional de Referências Culturais: manual de aplicação. Brasília: Instituto do Patrimônio Histórico e Artístico Nacional, 2000.

Patrimônio Imaterial: o registro do patrimônio imaterial: dossiê final das atividades da Comissão e do Grupo de Trabalho Patrimônio Imaterial. Brasília: Ministério da Cultura /Instituto do Patrimônio Histórico e Artístico Nacional, 4. ed, 2006.

OOSTERBEEK, Luiz; Reis, Milena das Graças Oliveira. Terras de Preto em Terras da Santa: Itamatatiua e as suas dinâmicas quilombolas. Cadernos de Pesquisa, São Luís, v. 19, n. 1, p. 7-15, 2012.

PEREIRA, Cleyciane Cássia Moreira. Mitos da cultura africana: elementos de informação e preservação da memória na Comunidade Quilombola Alcantarense de Itamatatiua. João Pessoa: UFPB, 2011. (Dissertação de Mestrado) - UFPB, João Pessoa, 2011.

QUEIROZ, Luiz Antônio Pacheco de. Água fria é no pote do Cariri Cearense. São Cristóvão: UFS, 2015. (Dissertação de Mestrado em Arqueologia) - UFS, São Cristóvão, 2015.

REGO, Herbert Moura. As panelas de barro de Pernambuco - do século XIX ao XXI. Recife: UFPE, 2013. (Dissertação de Mestrado em Arqueologia). UFPE, Recife, 2013.

RUIBAL, Alfredo González. El giro poscolonial: hacia una etnoarqueología crítica. En Departament d'Arqueologia i Antropologia. Institució Milà i Fontanals - CSIC (eds.).

Etnoarqueología de la Prehistoria: Más allá de la analogía. Treballs d'Etnoarqueologia, 6, CSIC, Madrid, p. 41-59, 2006.

De la etnoarqueología a la Arqueología del presente. In: SALAZAR. J.; DOMINGO, I.; ASKARRÁGA, J.; BONET, H. (Coords.). Mundos tribales: una visión etnoarqueológica. Valencia: Museo de Prehistoria, p. 16-27, 2009.

SILVA, Fabíola Andrea. Etnoarqueologia: Uma perspectiva Arqueológica para o Estudo da Cultura Material. Métis (UCS), v. 8, p. 121-139, 2009.

SILVA, Fabíola Andrea; GARCIA, Lorena. Território e memória dos Asurini do Xingu: Arqueologia Colaborativa na T.I. Kuatinemu, Pará. Amazônica: Revista de Antropologia (Online), v. 7, p. 74-99, 2015.

SOARES, Inês Virgínia P. Direito ao (do) Patrimônio Cultural Brasileiro. Belo Horizonte: Fórum, 2009.

\begin{tabular}{|l|l|l|l|l|l|l|}
\hline (C) Rev. Arqueologia Pública & Campinas, SP & v. & n. & p. & mês/ano & ISSN 2237-8294
\end{tabular}


SOUSA, Leilane Barbosa de; BARROSO, Maria Grasiela Teixeira. Pesquisa etnográfica: evolução e contribuição para a enfermagem. Escola Anna Nery Revista de Enfermagem, v. 1 , n. 12 , p. 150-155, 2008. 